Meta

Journal des traducteurs

Translators' Journal

\title{
Les outils du traducteur ou les mauvais ouvriers ont toujours de mauvais outils
}

\section{Irène V. Spilka}

Volume 13, numéro 3, septembre 1968

URI : https://id.erudit.org/iderudit/017813ar

DOI : https://doi.org/10.7202/017813ar

Aller au sommaire du numéro

Éditeur(s)

Les Presses de l'Université de Montréal

ISSN

0026-0452 (imprimé)

1492-1421 (numérique)

Découvrir la revue

Citer ce document

Spilka, I. V. (1968). Les outils du traducteur ou les mauvais ouvriers ont

toujours de mauvais outils. Meta, 13(3), 158-158.

https://doi.org/10.7202/017813ar d'utilisation que vous pouvez consulter en ligne. 


\section{Les outils du traducteur}

ou Les mauvais ouvriers ont toujours de mauvais outils

Sans doute ne serait-il pas mauvais que notre rubrique s'enrichisse, sinon d'un index des livres à ne pas consulter, au moins d'un chapitre indiquant (j'allais dire la «cote morale ») la cote linguistique ou tout simplement la valeur des ouvrages spécialisés offerts aux traducteurs et au public. Certains d'entre eux méritent sûrement la mention «à déconseiller 》, tel le Mathematics Dictionary (Multilengual [sic] Edition), publié par la maison Van Nostrand (New York, Londres, Boston, Toronto, Prineeton) dont la section French-English renferme à elle seule un joli collier de perles. En voici quelques-unes dont nos lecteurs pourront enrichir leur trésor de la langue franglaise.

Disons tout de suite qu'une place importante $y$ est faite aux simples fautes d'orthographe et au banal barbarisme: un critique bénévole en a relevé 392, nous n'en demandions pas tant! Les calques viennent au second rang, et l'on se réjouit d'apprendre qu'il existe des «nombres tordus» (winding numbers), des « calculatoires 》 (calculators) où, tout naturellement, s'effectuent des « calculations 》 (faut-il citer l'anglais?) quand ce ne sont pas des «computations». Enfin les inventions pures y ont une saveur sui generis qui eût fait pâlir d'envie le plus téméraire poète surréaliste. N'est-il pas joli, en effet, ce petit mot de « cuspe» pour dire pointe? Et «minuende » pour désigner le premier nombre d'une soustraction? De quoi faire pâmer une Précieuse. Mais on se laisse emporter par le «momentume» de la meilleuse écartante et cela risque de nous entraîner dans l'énumérabilité total, ce qui serait fâcheux pour le complex simplicieux que constitue ce petit recueil sans nul suite.

Nous nous arrêtons donc ici et nous invitons nos aimables abonnés à nous faire part à leur tour de leurs découvertes en matière de cuirs, velours, coquilles, perles et autres objets précieux du même genre. Nous serons heureux d'en orner nos outils.

I.V.S. 